\title{
Robotic versus laparoscopic Gastrectomy for gastric cancer: a systematic review and updated meta-analysis
}

\author{
Ke Chen ${ }^{1}$, Yu Pan ${ }^{1}$, Bin Zhang ${ }^{1}$, Hendi Maher ${ }^{2}$, Xian-fa Wang ${ }^{1}$ and Xiu-jun Cai ${ }^{\text {* }}$
}

\begin{abstract}
Background: Advanced minimally invasive techniques including robotic surgery are being employed with increasing frequency around the world, primarily in order to improve the surgical outcomes of laparoscopic gastrectomy (LG). We conducted a systematic review and meta-analysis to evaluate the feasibility, safety and efficacy of robotic gastrectomy (RG).

Methods: Studies, which compared surgical outcomes between LG and RG, were retrieved from medical databases before May 2017. Outcomes of interest were estimated as weighted mean difference (WMD) or risk ratio (RR) using the randomeffects model. The software Review Manage version 5.1 was used for all calculations.

Results: Nineteen comparative studies with 5953 patients were included in this analysis. Compared with LG, RG was associated with longer operation time (WMD $=-49.05 \mathrm{~min} ; 95 \% \mathrm{Cl}:-58.18 \sim-39.91, P<0.01)$, less intraoperative blood loss (WMD $=24.38 \mathrm{ml} ; 95 \% \mathrm{Cl}: 12.32 \sim 36.43, P<0.01)$, earlier time to oral intake $(\mathrm{WMD}=0.23$ days; $95 \% \mathrm{Cl}: 0.13 \sim 0.34$, $P<0.01$ ), and a higher expense (WMD $=-3944.8$ USD; 95\% Cl: $-4943.5 \sim-2946.2, P<0.01)$. There was no significant difference between RG and LG regarding time to flatus, hospitalization, morbidity, mortality, harvested lymph nodes, and cancer recurrence.
\end{abstract}

Conclusions: RG can be performed as safely as LG. However, it will take more effort to decrease operation time and expense.

Keywords: Laparoscopy, Robot, Gastrectomy, Stomach neoplasms, Morbidity, Meta-analysis

\section{Background}

Laparoscopic gastrectomy (LG) has been widely used for the treatment of gastric cancer and a number of other different minimally invasive procedures have been developed to date $[1,2]$. There are several benefits for patients; including better cosmesis, reduced pain, early recovery of intestinal function, and shorter hospital stay, while maintaining comparable oncologic safety [1-4].

Robotic surgery was first put into practice in 2000, after being approved by the US Food and Drug Administration (FDA). It plays an essential role in ergonomics and offers advantages such as motion scaling, less fatigue, tremor filtering, seven degrees of wrist-like motion, and three-dimensional vision $[5,6]$. Surgeons

\footnotetext{
* Correspondence: caixiujunzju@163.com

${ }^{1}$ Department of General Surgery, Sir Run Run Shaw Hospital, School of Medicine, Zhejiang University, 3 East Qingchun Road, Hangzhou, Zhejiang Province 310016, China

Full list of author information is available at the end of the article
}

hoped that such innovative technology could overcome some limitations innate to traditional laparoscopic surgery. Thus, experienced laparoscopic surgeons are increasingly trying to develop new procedures that best exploit the capabilities of robotic surgery in the treatment of gastric cancer [7].

Nonetheless, the present status of robotic gastrectomy (RG) is, as of the writing of this paper, still restricted and this is in part to due to the lack of randomized controlled trials (RCTs). Several previous studies including meta-analyses have argued that RG can be a more effective and safer operation in comparison with conventional LG. In spite of these studies, many questions still need to be answered, most notably, RG's efficacy with regard to oncologic, long-term survival outcomes and its costeffectiveness. Moreover, a series of studies on RG for the treatments of gastric cancer have been recently published. These studies are meaningful in highlighting the 
status of RG in the treatment of gastric cancer. Therefore, this paper's current research is intended to conduct a comprehensive systematic review of all the currently available literature and a meta-analysis of RG in comparison to LG in order to assess the feasibility, security and efficacy of RG.

\section{Methods}

\section{Search strategy}

A systematic search of Web of Science, Cochrane Library, Embase, and PubMed was conducted to find studies comparing RG and LG for gastric cancer treatment published up until May 2017. Search terms included "gastric carcinoma", "gastric cancer", "laparoscopic", "robotic", and "gastrectomy". The links in search results and references were also reviewed to find the additional literature. Based on the language competencies of the reviewers, English and Chinese were the only languages of searched papers.

\section{Eligibility criteria}

The standards for research were comparative, using peer-reviewed studies of RG versus LG in gastric cancer for which the full texts were available. The most recent study or the study with the most subjects was chosen if overlapping research studies were found. Articles including any of the following were excluded: (1) Non-comparative studies such as letters, reviews, comments, posters, protocols, et al. (2) Studies including non-gastric carcinoma cases such as gastrointestinal stromal tumors, or benign gastric diseases; (3) Studies in which less than 2 of the interesting indices were reported.

\section{Data extraction and quality assessment}

Two reviewers (Chen K and Pan Y) reviewed the publications thoroughly and independently. Data extracted included the following items: author, region, operation time, intraoperative estimated blood loss (EBL), time to flatus, time to oral intake, length of hospital stay (LOS), morbidity, mortality, costs, retrieved lymph nodes (RLN), proximal and distal margin distance, and long-term oncologic outcomes. In accordance with the morbidity reporting system of Memorial Sloan-Kettering Cancer Center [8], postoperative complications were categorized into medical complications (respiratory, cardiovascular, metabolic events, deep venous thrombosis, phlebitis, et al.) or surgical complications (bleeding, any complication required reoperation, anastomotic leakage or stricture, delayed gastric emptying, et al.). The means and standard deviations (SDs) were estimated as described by Hozo et al. [9] if the research offered medians and ranges. The choice of the articles included in this review adhered to the Preferred Reporting Items for Systematic Reviews and Meta-Analyses statement (PRISMA). The Newcastle-Ottawa Quality Assessment Scale (NOS) was utilized to evaluate the research quality (http://www.ohri.ca/programs/clinical_epidemiology/oxford .asp). The scale ranges from 0 to 9 stars: research with a score higher than or equal to 6 could be deemed as methodologically sound.

\section{Subgroup analysis}

The uneven distribution of the surgical extension between the groups could affect the outcomes. Therefore, to eliminate the bias, a subgroup analysis of total or distal gastrectomy was conducted. It has been reported that robotic surgery may benefit obese patients, because of improved visualization, instrumentation, and ergonomics [10]. Therefore, we conducted a subgroup analysis to analyze the impact of operation-related factors on body mass index (BMI).

\section{Statistical analysis}

The risk ratio (RR) was utilized to analyze the dichotomous variables and the weighted mean difference (WMD) was utilized to assess the continuous variables. Based on DerSimonian and Laird's approach, the randomeffects model was utilized to account for clinical heterogeneity, which refers to diversity in a sense that is relevant for clinical situations. According to the overall complication, the potential publication bias was determined by carrying out an informal visual inspection of funnel plots. The software of Review Manager version 5.1 (RevMan 5.1) was used to conduct data analysis. $P<0.05$ was considered statistically significant.

\section{Results}

\section{Studies selected}

A total of 378 potential articles, which were published from 1996 to 2017, were found. 37 articles were chosen based on the titles and abstracts, and then a thorough check of each text was conducted. Seven of them failed to meet our standards and were excluded. A further eleven papers were excluded due to overlapping patient cohorts (one from Hospital Niguarda Ca Granda, Italy [11]; one from Fujita Health University, Japan [12]; one from Taipei Veterans General Hospital, Taiwan [13]; four from Yonsei University, Korea [14-17]; four from National Cancer Center, Korea [18-21]). Finally, a total of nineteen studies were included for final meta-analysis [22-40]. A flow chart of the search strategies, which contains reasons for the exclusion of studies, is elucidated in Fig. 1.

\section{Study characteristics and quality}

A total of 5953 patients were included in the analysis with 4123 undergoing LG (69.3\%) and 1830 undergoing RG (30.7\%). Most of the studies came from East Asia (10 Korea, 2 Japan, 4 China, 1 Taiwan) and 2 research studies came from Italy. The baseline features of the included studies are shown in Table 1; the evaluation of 
Abstracts excluded because of not comparing LG and RG

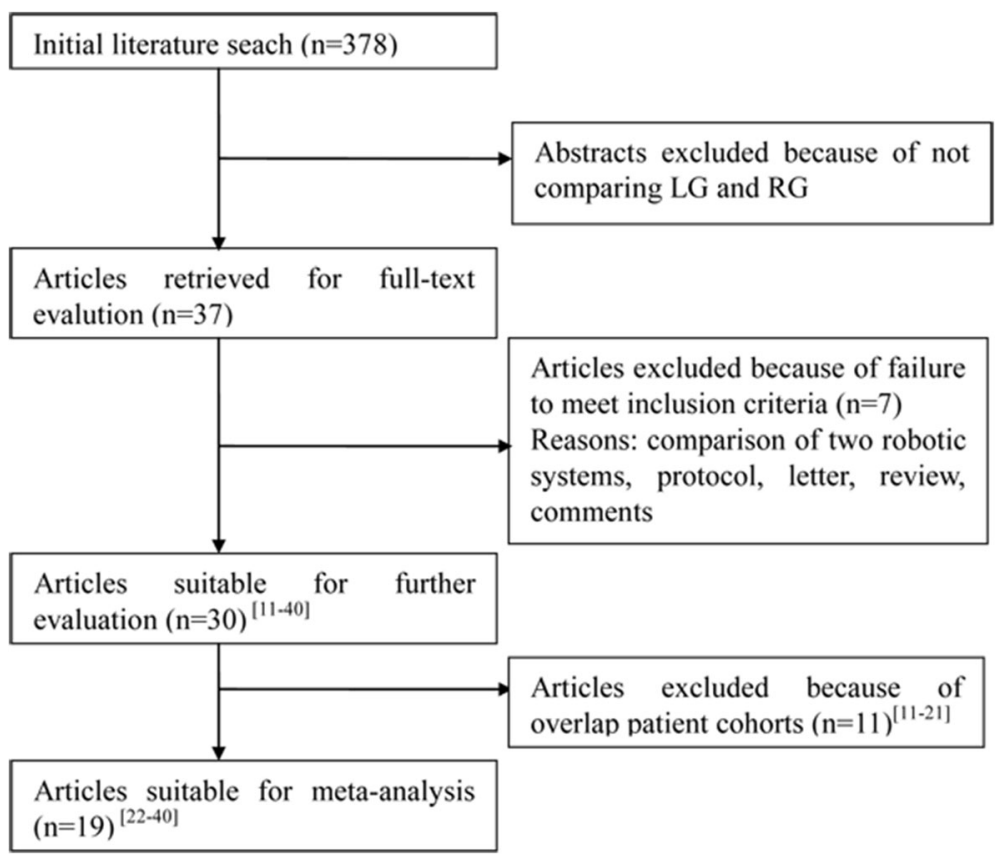

Fig. 1 Flow chart of literature search strategies

Table 1 Summary of studies included in the meta-analysis

\begin{tabular}{|c|c|c|c|c|c|c|c|c|c|c|c|}
\hline \multirow[t]{2}{*}{ Author } & \multirow[t]{2}{*}{ Region } & \multirow{2}{*}{$\begin{array}{l}\text { Study } \\
\text { design }\end{array}$} & \multirow[t]{2}{*}{ Year } & \multirow{2}{*}{$\begin{array}{l}\text { Study } \\
\text { period }\end{array}$} & \multicolumn{2}{|c|}{ Sample size } & \multirow{2}{*}{$\begin{array}{l}\text { Level of } \\
\text { lymphadenectomy }\end{array}$} & \multirow{2}{*}{$\begin{array}{l}\text { Surgical } \\
\text { extension }\end{array}$} & \multirow[t]{2}{*}{ Reconstruction } & \multicolumn{2}{|c|}{ Conversion (\%) } \\
\hline & & & & & $\mathrm{LG}$ & $\mathrm{RG}$ & & & & LG & $R G$ \\
\hline Pugliese & Italy & OCS (R) & 2010 & 2000-2009 & 48 & 16 & D2 & $\mathrm{D}$ & $R-Y$ & $3(6)$ & $2(12)$ \\
\hline Kim MC & Korea & OCS (P) & 2010 & 2007-2008 & 11 & 16 & $D 1+\beta, D 2$ & $\mathrm{D}$ & $B-I, B-I I$ & 0 & 0 \\
\hline Kim KM & Korea & OCS (P) & 2012 & 2005-2010 & 861 & 436 & $D 1+a / \beta, D 2$ & $\mathrm{D}, \mathrm{T}$ & B-I, B-II, R-Y & NR & NR \\
\hline Son SY & Korea & OCS (R) & 2012 & 2007-2011 & 42 & 21 & $D 1+\beta, D 2$ & $D, P, T$ & $B-I, B-I I, R-Y$ & NR & NR \\
\hline Kang & Korea & OCS (P) & 2012 & 2008-2011 & 282 & 100 & $D 1+\alpha / \beta, D 2$ & $\mathrm{D}, \mathrm{T}$ & B-I, B-II, R-Y & $E$ & 0 \\
\hline Zhang & China & OCS (R) & 2012 & 2009-2011 & 70 & 97 & D2 & $D, P, T$ & B-I, B-II, R-Y & 0 & 0 \\
\hline Hyun & Korea & OCS (P) & 2013 & 2009-2010 & 83 & 38 & $D 1+\alpha / \beta, D 2$ & $\mathrm{D}, \mathrm{T}$ & B-I, B-II, R-Y & 0 & 0 \\
\hline Son $T$ & Korea & OCS (R) & 2014 & 2003-2010 & 58 & 51 & D2 & $\mathrm{T}$ & $R-Y$ & 0 & 0 \\
\hline Noshiro & Japan & OCS (P) & 2014 & 2010-2012 & 160 & 21 & $D 1+a / \beta, D 2$ & $\mathrm{D}$ & B-I, B-II, R-Y & 0 & 0 \\
\hline Huang & Taiwan & OCS (P) & 2014 & 2008-2014 & 73 & 72 & $D 1+a / \beta, D 2$ & $\mathrm{D}, \mathrm{T}$ & $B-1, R-Y$ & NR & NR \\
\hline Zhou & China & OCS (R) & 2014 & 2010-2013 & 394 & 120 & $D 1+a / \beta, D 2$ & $D, P, T$ & B-I, B-II, R-Y & $E$ & E \\
\hline Liu & China & OCS (R) & 2014 & 2012-2013 & 100 & 100 & D2 & $D, P, T$ & B-I, B-II, R-Y & $1(1)$ & 0 \\
\hline Lee & Korea & OCS (P) & 2015 & 2003-2010 & 267 & 133 & D2 & $\mathrm{D}$ & B-I, B-II, R-Y & NR & NR \\
\hline Han & Korea & OCS (R) & 2015 & 2008-2013 & 68 & 68 & $D 1+\beta$ & PPG & GG & 0 & 0 \\
\hline Park & Korea & OCS (P) & 2015 & 2009-2011 & 612 & 145 & $D 1+a / \beta$ & $\mathrm{D}, \mathrm{T}$ & B-I, B-II, R-Y & 10(1.6) & $3(2.0)$ \\
\hline Suda & Japan & OCS (R) & 2015 & 2009-2012 & 438 & 88 & $D 1+a / \beta, D 2$ & $\mathrm{D}, \mathrm{T}$ & B-I, B-II, R-Y & 0 & 0 \\
\hline Kim HI & Korea & OCS (P) & 2016 & 2011-2012 & 185 & 185 & $D 1+a / \beta, D 2$ & $\mathrm{D}, \mathrm{T}$ & B-I, B-II, R-Y & $2(1.1)$ & $1(0.5)$ \\
\hline Shen & China & OCS (R) & 2016 & 2011-2014 & 330 & 93 & $D 1+\alpha / \beta, D 2$ & $\mathrm{D}, \mathrm{T}$ & B-I, B-II, R-Y & 0 & 0 \\
\hline Cianchi & Italy & OCS (R) & 2016 & $2008-2015$ & 41 & 30 & $\mathrm{D} 1+a / \beta, \mathrm{D} 2$ & $\mathrm{D}$ & B-II, R-Y & 0 & 0 \\
\hline
\end{tabular}

OCS observational clinical study, $P$ prospectively collected data, $R$ retrospectively collected data, $D$ distal gastrectomy, $P$ proximal gastrectomy, $T$ total gastrectomy $P P G$ pylorus-preserving gastrectomy, B-I Billroth-I, B-II Billroth-II, $R$-Y Roux-en-Y, GG gastro-gastro anastomosis, E exclude, NR not reported 
quality according to the NOS is shown in Table 2. NOS shows that four out of the 19 studies observed had 9 stars, one had 8 stars, seven had 7 stars and the remaining seven had 6 stars.

\section{Intraoperative effects and postoperative recovery}

As shown in Table 1, three studies did not report the information of conversion; two studies excluded the conversion cases, whereas another nine research studies had no conversion. The pooled data based on four studies, which reported conversion cases, showed similar conversion rates between groups $(\mathrm{RR}=0.88,95 \% \mathrm{CI}: 0.36 \sim 2.17$, $P=0.78$ ). A longer operation time for RG than for $L G$ was reported in the majority of research and meta-analysis revealed that the average operation time of LG was $49.05 \mathrm{~min}$ shorter than RG (WMD = $-49.05 \mathrm{~min}$; 95\% CI: $-58.18 \sim-39.91, P<0.01$ ) (Fig. 2a). Intraoperative EBL was reported in eighteen of the research studies, which was lower in RG than LG (WMD $=24.38 \mathrm{ml}$; 95\% CI: $12.32 \sim 36.43, P<0.01$ ) (Fig. 2 b).

The pooled mean time to first flatus indicated no significant difference between the two groups (WMD $=0.09$ days;
95\% CI: $-0.10 \sim 0.27, P=0.36$ ) (Fig. 2 c). Nonetheless, according to the meta-analysis, the mean time to restart oral intake was longer in LG than in RG (WMD $=0.23$ days; 95\% CI: $0.13 \sim 0.34, P<0.01$ ) (Fig. $2 d$ ). All studies reported the LOS. According to the pooled data, a significant difference did not exist between the two groups with regard to $\mathrm{LOS}$ (WMD $=0.35$ days; $95 \% \mathrm{CI}:-0.25 \sim 0.95$, $P=0.25$ ) (Fig. 2e). All intraoperative effects and postoperative recovery outcomes are summarized in Table 3 .

\section{Morbidity and mortality}

All studies reported adverse incidents ranging from $0 \%$ to $47.4 \%$ in RG and from $4.3 \%$ to $38.6 \%$ in LG. No significant difference in the rate of overall postoperative complications was identified between the groups of RG and LG (RR $=0.96,95 \%$ CI: $0.82 \sim 1.13, P=0.65)$ (Fig. 3a). Symmetry was shown in the visual inspection of the funnel plot, showing no severe publication bias (Fig. 4). After further analysis, surgical complications were similar between groups $(\mathrm{RR}=0.87,95 \% \mathrm{CI}: 0.72 \sim 1.05$, $P=0.15)$ (Fig. $3 \mathrm{~b}$ ), as were the medical complications $(\mathrm{RR}=1.34,95 \%$ CI: $0.75 \sim 2.40, P=0.32)$ (Fig. 3c).

Table 2 Quality assessment based on the NOS for observational studies

\begin{tabular}{|c|c|c|c|c|c|c|c|c|c|}
\hline \multirow[t]{2}{*}{ Author } & \multicolumn{4}{|c|}{ Selection (Out of 4) } & \multirow{2}{*}{$\begin{array}{l}\text { Comparability } \\
\text { (Out of 2) }\end{array}$} & \multicolumn{3}{|c|}{ Outcomes (Out of 3) } & \multirow{2}{*}{$\begin{array}{l}\text { Total } \\
\text { (Out of 9) }\end{array}$} \\
\hline & (1) & (2) & (3) & (4) & & (5) & (6) & (7) & \\
\hline Pugliese & * & * & $*$ & * & $* *$ & * & $*$ & * & 9 \\
\hline Kim MC & * & * & $*$ & $*$ & $*$ & * & & & 6 \\
\hline Kim KM & $*$ & * & $*$ & $*$ & * & * & & & 6 \\
\hline Son SY & $*$ & * & $*$ & * & ** & * & & & 7 \\
\hline Kang & $*$ & * & $*$ & * & $*$ & * & & & 6 \\
\hline Zhang & $*$ & * & $*$ & * & $* *$ & * & & & 7 \\
\hline Hyun & $*$ & * & $*$ & * & $*$ & * & & & 6 \\
\hline Son $\mathrm{T}$ & $*$ & * & $*$ & * & $* *$ & * & $*$ & $*$ & 9 \\
\hline Noshiro & $*$ & * & $*$ & $*$ & $* *$ & * & & & 7 \\
\hline Huang & * & * & * & * & $* *$ & * & & & 7 \\
\hline Zhou & $*$ & $*$ & $*$ & $*$ & $* *$ & * & $*$ & $*$ & 9 \\
\hline Liu & $*$ & * & $*$ & * & $* *$ & $*$ & & & 7 \\
\hline Lee & $*$ & $*$ & $*$ & $*$ & * & * & $*$ & $*$ & 8 \\
\hline Han & * & * & * & * & $* *$ & * & $*$ & $*$ & 9 \\
\hline Park & $*$ & * & $*$ & * & * & * & & & 6 \\
\hline Suda & * & * & $*$ & * & * & * & & $*$ & 7 \\
\hline Kim HI & $*$ & * & $*$ & * & * & * & & & 6 \\
\hline Shen & * & * & $*$ & * & $* *$ & * & & & 7 \\
\hline Cianchi & $*$ & * & $*$ & * & * & * & & & 6 \\
\hline
\end{tabular}

(1) representativeness of exposed cohort

(2) selection of nonexposed cohort

(3)ascertainment of exposure

(4) outcome not present at the start of the study

(5)assessment of outcomes

(6)length of follow-up

(7)adequacy of follow-up 
a

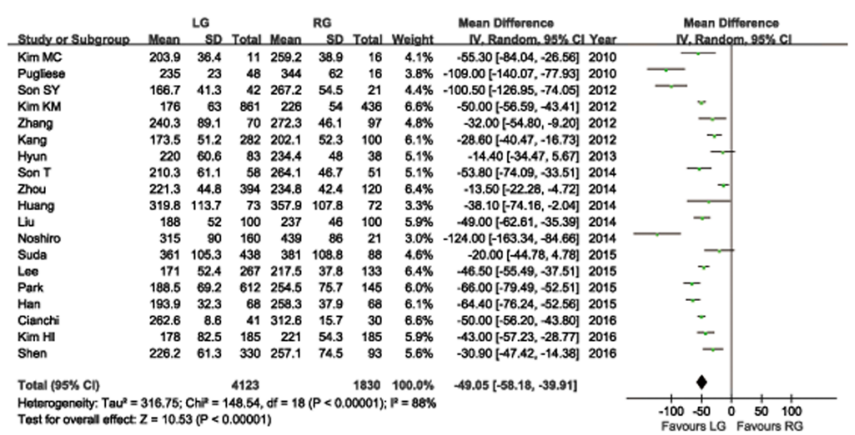

b

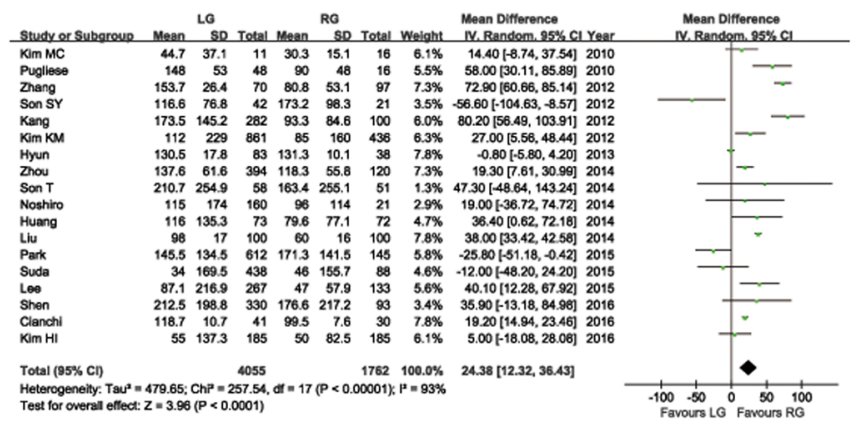

C

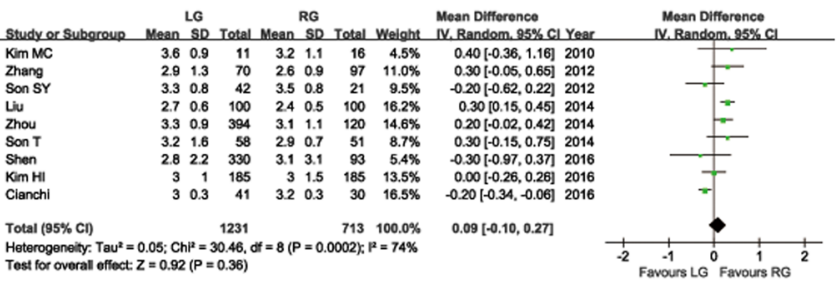

d

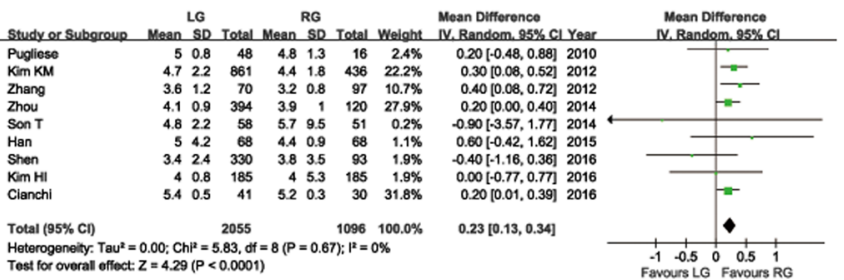

e

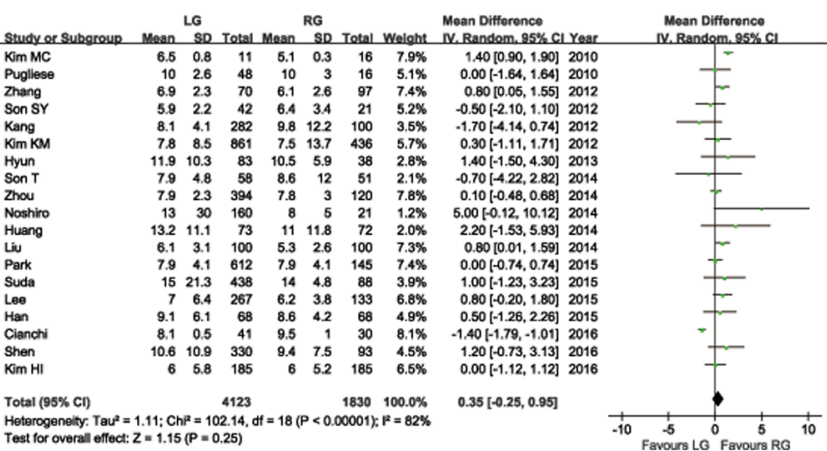

Fig. 2 Forest plot of the meta-analysis for intraoperative effects and postoperative recovery. a Operation time. b Estimated blood loss. c Time to first flatus. d Time to restart oral intake. e Length of postoperative hospital stay 
Table 3 Results of the meta-analysis

\begin{tabular}{|c|c|c|c|c|c|c|c|}
\hline \multirow[t]{2}{*}{ Outcomes } & \multirow{2}{*}{$\begin{array}{l}\text { No. of } \\
\text { studies }\end{array}$} & \multicolumn{2}{|c|}{ Sample size } & \multirow{2}{*}{$\begin{array}{l}\text { Heterogeneity } \\
\left(P, P^{2}\right)\end{array}$} & \multirow{2}{*}{$\begin{array}{l}\text { Overall } \\
\text { effect size }\end{array}$} & \multirow{2}{*}{$\begin{array}{l}95 \% \mathrm{Cl} \text { of } \\
\text { overall effect }\end{array}$} & \multirow[t]{2}{*}{$P$} \\
\hline & & LG & RG & & & & \\
\hline Conversion & 4 & 16 & 6 & $0.68,0 \%$ & $\mathrm{RR}=0.88$ & $0.36 \sim 2.17$ & 0.78 \\
\hline Operation time (min) & 19 & 4123 & 1830 & $<0.001,88 \%$ & WMD $=-49.05$ & $-58.18 \sim-39.91$ & $<0.01$ \\
\hline Blood loss (mL) & 18 & 4055 & 1762 & $<0.001,93 \%$ & WMD =24.38 & $12.32 \sim 36.43$ & $<0.01$ \\
\hline Time to first flatus (days) & 9 & 1231 & 713 & $<0.001,74 \%$ & WMD $=0.09$ & $-0.10 \sim 0.27$ & 0.36 \\
\hline Time to oral intake (days) & 9 & 2055 & 1096 & $0.67,0 \%$ & $\mathrm{WMD}=0.23$ & $0.13 \sim 0.34$ & $<0.01$ \\
\hline Hospital stay (days) & 19 & 4123 & 1830 & $<0.001,82 \%$ & WMD $=0.35$ & $-0.25 \sim 0.95$ & 0.25 \\
\hline Overall complications & 19 & 4123 & 1830 & $0.82,0 \%$ & $\mathrm{RR}=0.96$ & $0.82 \sim 1.13$ & 0.65 \\
\hline Surgical complications & 17 & 3234 & 1552 & $0.52,0 \%$ & $\mathrm{RR}=0.87$ & $0.72 \sim 1.05$ & 0.15 \\
\hline Medical complications & 12 & 2137 & 907 & $0.82,0 \%$ & $\mathrm{RR}=1.34$ & $0.75 \sim 2.40$ & 0.32 \\
\hline Reoperation & 7 & 1796 & 789 & $0.35,11 \%$ & $\mathrm{RR}=0.69$ & $0.29 \sim 1.62$ & 0.39 \\
\hline Mortality & 7 & 2131 & 838 & $0.91,0 \%$ & $\mathrm{RR}=0.67$ & $0.26 \sim 1.74$ & 0.41 \\
\hline Retrieved lymph nodes & 17 & 3229 & 1585 & $<0.001,86 \%$ & WMD $=-1.44$ & $-3.26 \sim 0.37$ & 0.12 \\
\hline Proximal margin $(\mathrm{cm})$ & 9 & 2006 & 1024 & $0.21,26 \%$ & WMD $=-0.14$ & $-0.36 \sim 0.07$ & 0.18 \\
\hline Distal margin $(\mathrm{cm})$ & 8 & 1948 & 973 & $<0.001,81 \%$ & WMD $=0.09$ & $-0.46 \sim 0.65$ & 0.74 \\
\hline Recurrence & 3 & 500 & 187 & $0.39,0 \%$ & $\mathrm{RR}=1.09$ & $0.57 \sim 2.05$ & 0.80 \\
\hline Cost (USD) & 4 & 390 & 384 & $<0.001,93 \%$ & $W M D=-3944.8$ & $-4943.5 \sim-2946.2$ & $<0.01$ \\
\hline
\end{tabular}

Reoperation cases were reported in seven studies, and there was no significant difference in the reoperation rates $(\mathrm{RR}=0.69,95 \% \mathrm{CI}: 0.29 \sim 1.62, P=0.39$ ) (Fig. $3 \mathrm{~d}$ ). Also, seven studies reported mortality and no significant difference could be found in postoperative mortality $(\mathrm{RR}=0.67,95 \% \mathrm{CI}: 0.26 \sim 1.74, P=0.41)$ (Fig. $3 \mathrm{e})$. The specific reoperation and causes of mortality reported in the studies are summarized in Table 4. The meta-analysis results on morbidity and mortality are outlined in Table 3 .

\section{Oncologic outcomes and long-term survival}

The differences in the average number of RLNs were not considerable in the pooled statistics with a tendency towards a reduction in the LG group when compared to the RG group (WMD $=-1.44 ; 95 \% \mathrm{CI}:-3.26 \sim 0.37$, $P=0.12$ ) (Fig. 5a). The distal or proximal margin distances were described in nine studies. Meta-analysis of the proximal margin distances showed no significant difference between the two groups (WMD $=-0.14 \mathrm{~cm}$; 95\% CI: $-0.36 \sim 0.07, P=0.18$ ) (Fig. 5 b), the same applies to the distal margin distance $(W M D=0.09 \mathrm{~cm}$; 95\% CI: $-0.46 \sim 0.65, P=0.74$ ) (Fig. $5 \mathrm{c}$ ). Cancer recurrence was reported in three research studies and the pooled data indicated that the difference between RG and LG was not significant $(\mathrm{RR}=1.09,95 \% \mathrm{CI}$ : $0.57 \sim 2.05, P=0.80$ ). Long-term survival rates were reported in three research studies, and no considerable difference in the survival rates between the LG group and RG group could be found. In addition, during the follow-up time, no significant difference in the survival rates between both of the groups could be found in the studies of Lee et al. [34] and Han et al. [35] though they failed to report the particular survival rates. The metaanalysis of survival rates cannot be done due to the limited data. The systematic review outcomes of follow-up time, recurrence patterns and sites, and long-term survival rates are summarized in Table 5.

\section{Total cost}

Only four studies recorded their total cost and they all reported a higher cost for RG than LG. The metaanalysis demonstrated that the total cost of RG groups was significantly higher than LG groups (WMD $=-3944.8$ USD; 95\% CI: $-4943.5 \sim-2946.2, P<0.01$ ) (Fig. 6).

\section{Subgroup analysis of distal or total gastrectomy}

For the subgroup analysis of distal gastrectomy (DG), the RG group still holds the longer operation time $(P<0.01)$, lower EBL $(P<0.05)$ and with similar LOS, overall complications, mortality as well as RLN $(P>0.05)$. However, there was a reduced time to oral intake for RG, but with only a marginal difference compared to the LG group $(P=0.05)$. As for total gastrectomy $(\mathrm{TG})$, there is no large difference between the outcomes of operation time, EBL, time to oral intake, LOS, overall complications and mortality against DG subgroup analysis, the number of RLNs of RG was more than that of LG with a significant difference $(P=0.03)$. The subgroup analysis results of surgical extension are summarized in Table 6. Generally speaking, the difference in surgical extension had little effect on the overall meta-analysis results. 


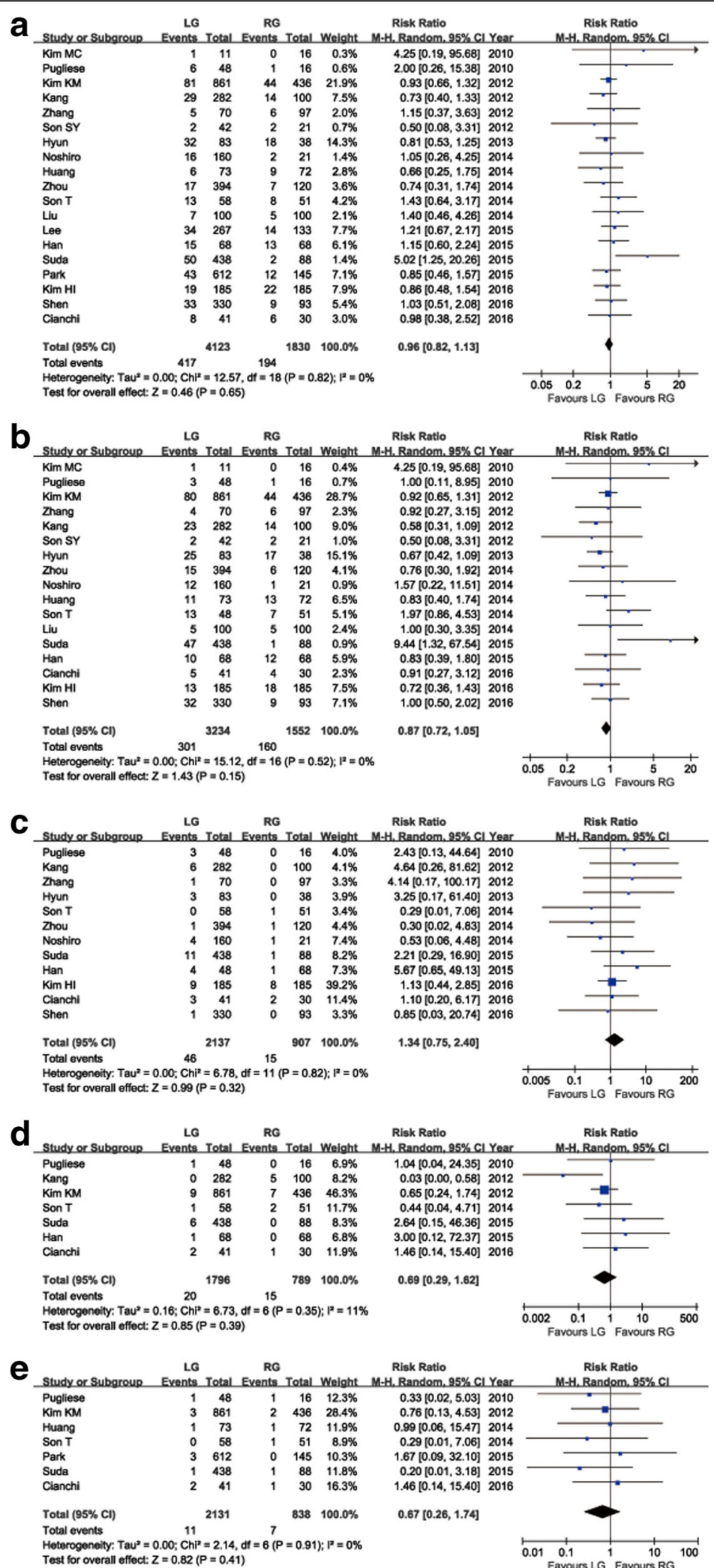

Fig. 3 Forest plot of the meta-analysis for morbidity and mortality. a Overall postoperative complications. b Surgical complications. c Medical complications. d Reoperation. e Mortality 


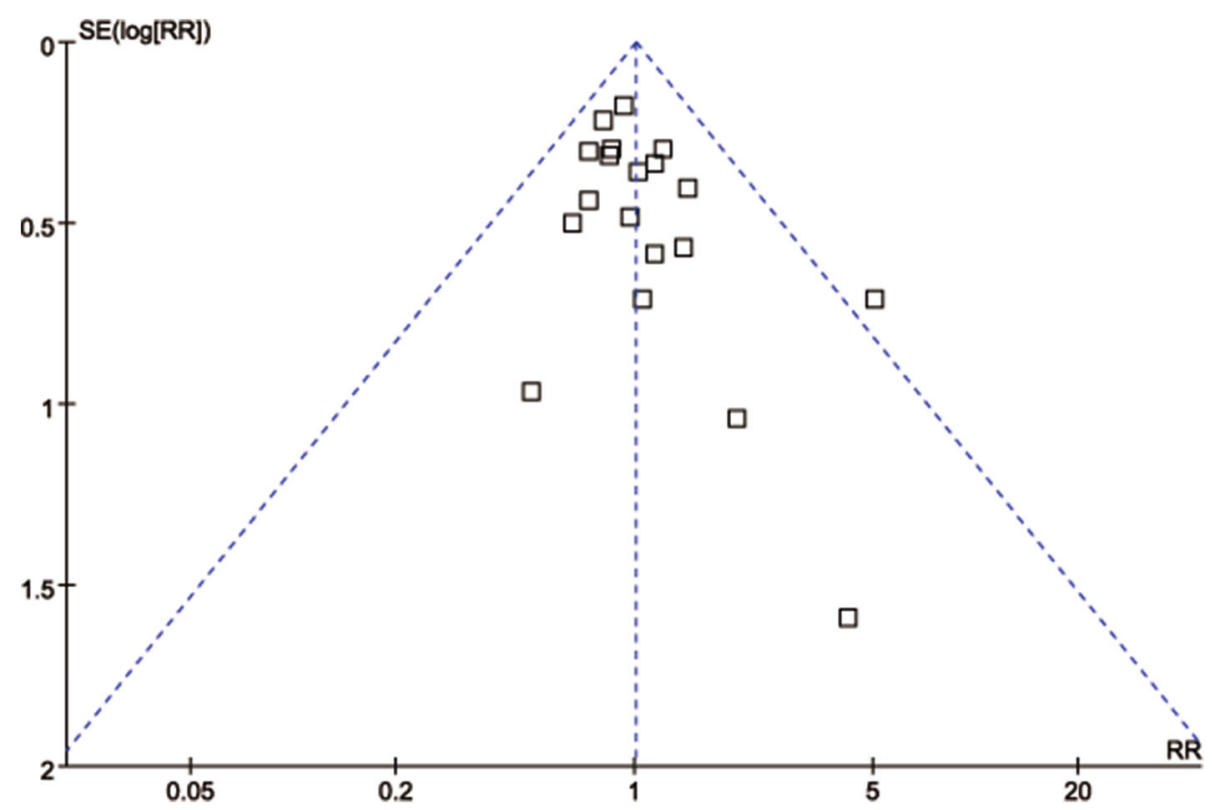

Fig. 4 Funnel plot of the overall postoperative complications

\section{Subgroup analysis of weight influence}

Only two studies had data for subgroup analysis based on weight $[28,34]$. The patients were divided based on preoperative BMI into non-overweight (BMI $<25 \mathrm{~kg} / \mathrm{m}^{2}$ ) and overweight $\left(\mathrm{BMI}>25 \mathrm{~kg} / \mathrm{m}^{2}\right)$ groups. In the nonoverweight subgroup, the RG group still had a longer operation time $(P<0.01)$, while in the overweight subgroup; the operation time was similar between groups $(P=0.27)$. In addition, there was no significant difference between LG and RG for the outcomes of EBL and RLNs regardless of overweight or non-overweight subgroup. Other perioperative outcomes cannot be analyzed due to the limited data. The subgroup analysis results based on weight are summarized in Table 7.

Table 4 Systematic review of the specific reoperation and death reasons

\begin{tabular}{|c|c|c|c|}
\hline Author & Group & Reoperation & Death \\
\hline \multirow[t]{2}{*}{ Pugliese } & LG & Enterocutaneous leak $(n=1)$ & Severe bleeding due to hepatic failure $(n=1)$ \\
\hline & RG & NC & Hemorrhagic stroke $(n=1)$ \\
\hline \multirow[t]{3}{*}{ Kim KM } & LG & Leak-related $(n=4)^{\mathrm{a}}$ & Leak-related $(n=2)^{a}$ \\
\hline & RG & Leak-related $(n=6)^{\mathrm{a}}$ & NC \\
\hline & RG & Leakage and obstruction $(n=5)$ & NC \\
\hline \multirow[t]{2}{*}{ Lee } & LG & Anastomotic leakage $(n=1)$ & NC \\
\hline & RG & $\begin{array}{l}\text { Anastomotic leakage }(n=1) \\
\text { anastomotic bleeding }(n=1)\end{array}$ & Anastomotic bleeding $(n=1)$ \\
\hline \multirow[t]{2}{*}{ Huang } & LG & NC & Duodenal stump leakage $(n=1)$ \\
\hline & $R G$ & NC & Gastrojejunostomy leakage $(n=1)$ \\
\hline Han & LG & $\begin{array}{l}\text { Intra-abdominal bleeding due } \\
\text { to liver capsular injury }(n=1)\end{array}$ & NC \\
\hline Park & LG & NC & $\begin{array}{l}\text { Immediate postoperative bleeding }(n=1) \text {, } \\
\text { mesenteric infarction }(n=1) \text {, septic shock } \\
\text { caused by afferent loop syndrome }(n=1)\end{array}$ \\
\hline \multirow[t]{2}{*}{ Cianchi } & LG & NC & $\begin{array}{l}\text { Duodenal stump leakage with peritonitis } \\
\text { and sepsis }(n=1) \text {, acute myocardial infarction } \\
(n=1)\end{array}$ \\
\hline & RG & Intestinal occlusion $(n=1)$ & Cerebral vascular accident $(n=1)$ \\
\hline
\end{tabular}




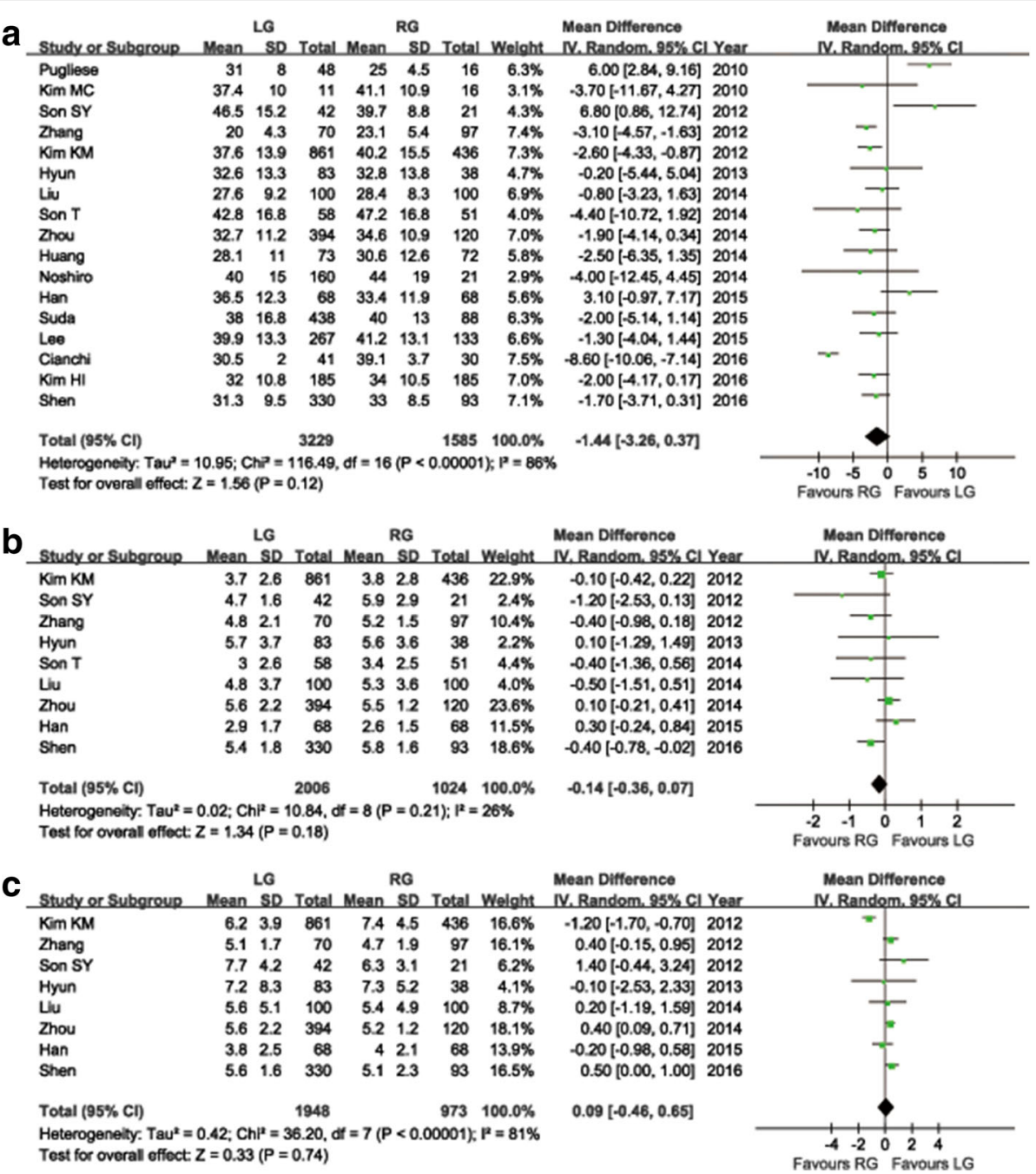

Fig. 5 Forest plot of the meta-analysis for oncologic outcomes. a Number of retrieved lymph nodes. b Proximal margin distances. c Distal margin distance. $\mathbf{d}$ Cancer recurrence

\section{Discussion}

The cost-effectiveness and definite advantages of RG have not been well documented, which is different when compared to the evolution of LG versus conventional open surgery [20]. However, the number of publications on RG has gradually increased in recent years. The oncologic outcomes, postoperative outcome, intraoperative effects and costs of a total of 1830 patients who underwent RG for gastric cancer treatment in 19 studies were reviewed as we believe such research would contribute to a more objective and comprehensive assessment of the current RG surgical status.

In spite of the considerable heterogeneity, the prolonged operating time in RG was shown in almost all the included research studies. The prolonged exposure time to pneumoperitoneum and the associated increased time of anesthesia is a major concern. Few publications describe the effect of longer operation times during RG.
However, previous research of LG in senior patients has shown that longer operation time did not result in detrimental effects with regard to surgical results [41]. Therefore, a prolonged operating time should not affect surgeons directly on conducting research on RG's new utility. Inevitably, the docking time was considered as an essential factor, which enhanced the operating time. The docking time was between $20 \mathrm{~min}$ to $60 \mathrm{~min}$ as reported in our study $[7,13,15,31]$, We found RG had longer operation times than LG by $49 \mathrm{~min}$, which suggested the 'true' time spent on operations was similar or even shorter than LG. Furthermore, with the increased utilization of the new robotic surgical system, operation times are expected to shorten. Several studies have reported that the da Vinci Xi robotic platform is more user-friendly and is easier to install in rectal and nephritic surgery $[42,43]$. As a result, we believed that RG is technically feasible with regard to operation time. 
Table 5 Systematic Review of Recurrence and Long-term Survivals

\begin{tabular}{|c|c|c|c|c|c|c|}
\hline Author & Group & Stage & Chemotherapy & Follow-up (mo) & Recurrence & Survival (\%) \\
\hline \multirow[t]{2}{*}{ Pugliese } & LG & \multirow[t]{2}{*}{ Any $\mathrm{TNM}_{0}$} & \multirow[t]{2}{*}{$\mathrm{T}_{3}$ or any $\mathrm{TN}_{+}$} & $53(3-112)$ & $8^{a}$ & $3 y-O S: 85 ; 5 y-O S: 83^{\&}$ \\
\hline & RG & & & $28(2-44)$ & $4^{\mathrm{a}}$ & $3 y-O S: 78^{\&}$ \\
\hline \multirow[t]{2}{*}{ Son $T$} & LG & \multirow[t]{2}{*}{ Any TNM } & \multirow[t]{2}{*}{ NR } & \multirow[t]{2}{*}{70} & $3^{\mathrm{b}}$ & 5y-DFS: 91.2; 5y-OS: 91.1 \\
\hline & RG & & & & $3^{b}$ & 5y-DFS: 90.2; 5y-OS: 89.5 \\
\hline \multirow[t]{2}{*}{ Zhou } & LG & \multirow[t]{2}{*}{ Any $\mathrm{TNM}_{0}$} & \multirow[t]{2}{*}{ Routinely } & \multirow[t]{2}{*}{$17(3-41)$} & 28 & $\begin{array}{l}\text { 1, 2, 3-OS: } 87.3,77.1,69.9 \\
\text { 3y-OS N_:82.6, 3y-OS N+:60.3 }\end{array}$ \\
\hline & RG & & & & 5 & $\begin{array}{l}\text { 1, 2, 3-OS: } 90.2,78.1,67.8 \\
\text { 3y-OS N_: } 84.4,3 y-O S N_{+}: 57.5\end{array}$ \\
\hline \multirow[t]{2}{*}{ Lee } & LG & \multirow[t]{2}{*}{ Any $\mathrm{TNM}_{0}$} & \multirow[t]{2}{*}{$N R$} & \multirow[t]{2}{*}{75} & \multirow[t]{2}{*}{ NR } & \multirow[t]{2}{*}{ NSD } \\
\hline & RG & & & & & \\
\hline \multirow[t]{2}{*}{ Han } & LG & \multirow[t]{2}{*}{$\mathrm{CT}_{1-2} \mathrm{~N}_{0} \mathrm{M}_{0}$} & 3 cases $(4.4 \%)^{\$}$ & 19.3 & 0 & \multirow[t]{2}{*}{ NSD } \\
\hline & RG & & 3 cases $(4.4 \%)^{\$}$ & 22.7 & 0 & \\
\hline
\end{tabular}

Follow-up time were shown as median (range) or median only

DFS disease-free survival, OS overall survival, y year, $N_{-}$negative nodal metastasis, $N_{+}$positive nodal metastasis, NR not report, NSD only reported no significant difference between two groups without specific survival rate

${ }^{\mathrm{a}}$ some patients had mixed tumor recurrence, identified recurrence in LG: local $(n=2)$, peritoneum $(n=2)$, liver $(n=1)$, lung $(n=2)$, bone $(n=1)$; identified recurrence in RG: peritoneum $(n=1)$, liver $(n=1)$, bone $(n=1)$. \&: for overall patients, $5 y-O S N_{-}: 97 \%, 5 y-O S N_{+}: 52 \%$

${ }^{\mathrm{b}} \mathrm{LG}$, peritoneum $(n=2)$, lung $(n=1)$; RG, breast $(n=1)$, splenic hilum $(n=1)$, ovary $(n=1)$. \#: 5 -fluorouracil + oxaliplatin intravenous chemotherapy. \$: because of advanced disease status after surgery

Surgeons have to go through a learning curve to master a technique. The surgical results, such as operation time, oncological outcomes and postoperative complications can be affected by surgeon's familiarity with the instrument, experience and assistant compliance. In general, before stabilization, LG should be conducted on around 40 to 60 cases [44]. The learning curve for RG was shorter for experienced surgeon who had performed LG, which is forecasted to be only 10 to 20 cases $[12,13,18,26]$. A surgeon experienced in laparoscopic surgery can conduct robotic surgery securely even in their first case [16]. Several studies investigated in this meta-analysis compared the initial and later experiences of robotic surgery $[12,13,18,26]$. The later cases performed by the same surgical team could progress toward shortening operation times.

Postoperative morbidity is the main indicator for assessing the safety and feasibility of one procedure. It is widely accepted that laparoscopic surgery for gastric cancer is safer and could have fewer complications than open surgery [45]. Our meta-analysis demonstrated a comparable complication rate in RG versus LG group, and the low heterogeneity regardless of overall, surgical or medical complications encourages us to believe that $\mathrm{RG}$ indeed is as safe as LG. Improvements such as three-dimension images and tremor filtering could theoretically contribute to safer implementations of the robotic system for gastrectomy and lymphadenectomy. According to the multivariate analyses in the Suda study, the application of RG was an important independent protective factor in regards to the postoperative complication [37]. Tokunaga et al. [46, 47] reported the incidences of overall adverse events after RG which were $14.2 \%$ and $22.2 \%$ based on their two-phase II studies, which are comparable to the rates of $19-27 \%$ in previous studies of LG $[48,49]$.

Obesity is one of the most significant health problems today and rates are still increasing around the world. Some studies claim obesity causes increased blood loss, operation time, and wound infection rate et al. [50, 51], whereas others did not observe any negative effect on surgical outcomes [52]. Recently, Harr et al. [10] showed

\begin{tabular}{|c|c|c|c|c|c|c|c|c|c|c|c|c|}
\hline \multirow[b]{2}{*}{ Study or subgroup } & \multicolumn{3}{|c|}{ LG } & \multicolumn{3}{|c|}{ RG } & \multicolumn{2}{|r|}{ Mean Difference } & \multirow{2}{*}{\multicolumn{4}{|c|}{$\begin{array}{l}\text { Mean Difference } \\
\text { N. Randem. } 95 \% \mathrm{Cl}\end{array}$}} \\
\hline & Maan & SD & Total & Mean & SD & Tetal & Welght & IX. Randem. $25 \% \mathrm{Cl}$ Yoar & & & & \\
\hline Znang & $5,243.4$ & $1,613.2$ & 70 & $8,564.5$ & 1,640 & 97 & $25.7 \%$ & $-3321.10[-3820.43,-2821.77] 2012$ & 4 & & & \\
\hline Eom 2012 & 6,071 & 2,160 & 62 & 11,402 & 1,822 & 30 & $22.7 \%$ & $-5331.00[-6203.98,-4588.02] 2012$ & 4 & & & \\
\hline Huang & $2,915.1$ & $1,341.4$ & 73 & $5,714.2$ & $1,591.7$ & 72 & $25.8 \%$ & $-2799.10[-3278.54,-2319.66] 2014$ & 4 & & & \\
\hline $\mathrm{Km} \mathbf{H I}$ & 8,960 & 1.667 .9 & 185 & 13,470 & 2,720 & 185 & $25.9 \%$ & $-4490.00[-4949.77,-4030.23] 2016$ & 4 & & & \\
\hline Total $(95 \% \mathrm{Cl})$ & & & 390 & & & $3 e 4$ & $100.0 \%$ & -3944.22 (-4943.45, -2946.19] & 4 & & & \\
\hline \multicolumn{9}{|c|}{$\begin{array}{l}\text { Heterogeneihy: Tau" }=947121.64 ; \text { ChP }=40.47, \mathrm{df}=3 \text { (P<0.00001) } \mathrm{P}=83 \% \\
\text { Test for oreral eflect: } Z=7.74(P<0.00001)\end{array}$} & -20 & Favours LG & Favours RG & 20 \\
\hline
\end{tabular}


Table 6 Results of the subgroup analysis of distal or total gastrectomy

\begin{tabular}{|c|c|c|c|c|c|c|c|}
\hline \multirow[t]{2}{*}{ Outcomes } & \multirow{2}{*}{$\begin{array}{l}\text { No. of } \\
\text { studies }\end{array}$} & \multicolumn{2}{|c|}{ Sample size } & \multirow{2}{*}{$\begin{array}{l}\text { Heterogeneity } \\
\left(P, P^{2}\right)\end{array}$} & \multirow{2}{*}{$\begin{array}{l}\text { Overall } \\
\text { effect size }\end{array}$} & \multirow{2}{*}{$\begin{array}{l}95 \% \mathrm{Cl} \text { of } \\
\text { overall effect }\end{array}$} & \multirow[t]{2}{*}{$P$} \\
\hline & & $\overline{\mathrm{LG}}$ & $\overline{R G}$ & & & & \\
\hline \multicolumn{8}{|c|}{ Operation time (min) } \\
\hline DG & 8 & 1635 & 453 & $<0.001,78 \%$ & $W M D=-57.08$ & $-68.62 \sim-45.54$ & $<0.01$ \\
\hline TG & 5 & 448 & 166 & $0.004,74 \%$ & $W M D=-42.62$ & $-66.72 \sim-18.52$ & $<0.01$ \\
\hline \multicolumn{8}{|c|}{ Blood loss (mL) } \\
\hline DG & 8 & 1635 & 453 & $<0.001,77 \%$ & WMD $=19.27$ & $3.86 \sim 34.68$ & 0.01 \\
\hline TG & 5 & 448 & 166 & $0.54,0 \%$ & WMD $=23.77$ & $1.97 \sim 45.56$ & 0.03 \\
\hline \multicolumn{8}{|c|}{ Time to oral intake (days) } \\
\hline DG & 3 & 344 & 116 & $0.49,0 \%$ & WMD $=0.18$ & $0.00 \sim 0.36$ & 0.05 \\
\hline TG & 3 & 251 & 100 & $0.71,0 \%$ & WMD $=-0.18$ & $-0.55 \sim 0.20$ & 0.36 \\
\hline \multicolumn{8}{|c|}{ Hospital stay (days) } \\
\hline DG & 8 & 1635 & 453 & $<0.001,92 \%$ & WMD $=0.52$ & $-0.69 \sim 1.74$ & 0.40 \\
\hline TG & 5 & 448 & 166 & $0.75,0 \%$ & WMD $=0.28$ & $-0.80 \sim 1.36$ & 0.61 \\
\hline \multicolumn{8}{|c|}{ Overall complications } \\
\hline DG & 8 & 1635 & 453 & $0.86,0 \%$ & $\mathrm{RR}=1.19$ & $0.83 \sim 1.71$ & 0.34 \\
\hline TG & 4 & 330 & 140 & $0.49,0 \%$ & $\mathrm{RR}=1.32$ & $0.80 \sim 2.18$ & 0.27 \\
\hline \multicolumn{8}{|l|}{ Mortality } \\
\hline DG & 4 & 942 & 213 & $0.84,0 \%$ & $\mathrm{RR}=0.84$ & $0.21 \sim 3.30$ & 0.80 \\
\hline TG & 2 & 194 & 81 & $0.55,0 \%$ & $\mathrm{RR}=0.15$ & $0.02 \sim 1.41$ & 0.10 \\
\hline \multicolumn{8}{|c|}{ Retrieved lymph nodes } \\
\hline DG & 8 & 1635 & 453 & $<0.001,92 \%$ & WMD $=-2.10$ & $-5.90 \sim 1.70$ & 0.28 \\
\hline TG & 5 & 448 & 166 & $0.63,0 \%$ & $\mathrm{WMD}=-2.51$ & $-4.83 \sim-0.19$ & 0.03 \\
\hline
\end{tabular}

$D G$ distal gastrectomy, $T G$ total gastrectomy

that the benefits of robotic methods were more evident in high versus normal BMI patients when performing a colostomy. The authors concluded that robotic surgery might overcome the difficulties associated with thick abdominal walls and excessive intra-abdominal fat, thanks to improved visualization, instrumentation, and ergonomics [10]. However, compared to other operations such as the colorectal or prostatic surgeries, which are in relatively narrow regions, the superiority of da Vinci over the laparoscopy may not be obvious, in that gastric surgery is conducted in the upper abdomen of a relatively spacious location. In our study, the overall mean operation time of RG and LG were similar in the overweight subgroups, contrasting with those in the nonoverweight subgroups, which implied RG to be superior to LG when used on overweight patients. However, the sample size of the overweight subgroups was not large enough to be conclusive.

Table 7 Results of the subgroup analysis of weight

\begin{tabular}{|c|c|c|c|c|c|c|c|}
\hline \multirow[t]{2}{*}{ Outcomes } & \multirow{2}{*}{$\begin{array}{l}\text { No. of } \\
\text { studies }\end{array}$} & \multicolumn{2}{|c|}{ Sample size } & \multirow{2}{*}{$\begin{array}{l}\text { Heterogeneity } \\
\left(P, P^{2}\right)\end{array}$} & \multirow{2}{*}{$\begin{array}{l}\text { Overall } \\
\text { effect size }\end{array}$} & \multirow{2}{*}{$\begin{array}{l}95 \% \mathrm{Cl} \text { of } \\
\text { overall effect }\end{array}$} & \multirow[t]{2}{*}{$P$} \\
\hline & & $\overline{L G}$ & $\mathrm{RG}$ & & & & \\
\hline \multicolumn{8}{|l|}{ Operation time (min) } \\
\hline non-overweight & 2 & 232 & 127 & $0.06,72 \%$ & WMD $=-37.63$ & $-62.82 \sim-12.43$ & $<0.01$ \\
\hline overweight & 2 & 118 & 44 & $0.008,86 \%$ & WMD $=-28.58$ & $-79.11 \sim 21.94$ & 0.27 \\
\hline \multicolumn{8}{|l|}{ Blood loss (mL) } \\
\hline non-overweight & 2 & 232 & 127 & $0.11,60 \%$ & $W M D=0.90$ & $-13.44 \sim 15.25$ & 0.90 \\
\hline overweight & 2 & 118 & 44 & $0.03,80 \%$ & WMD $=39.84$ & $-41.71 \sim 121.39$ & 0.34 \\
\hline \multicolumn{8}{|c|}{ Retrieved lymph nodes } \\
\hline non-overweight & 2 & 232 & 127 & $0.34,0 \%$ & WMD $=-1.88$ & $-4.78 \sim 1.01$ & 0.20 \\
\hline overweight & 2 & 118 & 44 & $0.03,79 \%$ & WMD $=4.32$ & $-4.10 \sim 12.74$ & 0.31 \\
\hline
\end{tabular}


The traditional straight forceps in LG fail to enable surgeons to reach deep-seated vessels and other areas, like the supra pancreatic one, in which the dissection of lymph nodes around the splenic hilum, splenic artery, and hepatic artery areas is deemed extremely hard. The tremor filtering, wristed instruments, as well as stable exposure and high-solution image can help surgeons thoroughly retrieve the lymph nodes around the delicate areas [21]. According to one included study, the amount of RLNs was considerably higher with robotic surgery in the splenic hilum and splenic artery areas [29]. Our meta-analysis shows adequate RLNs with means of 35.4 and 36.1 in the LG and RG groups, respectively. The mean number of RLNs of RG was more than that of LG with a marginal difference observed in the pooled data, even though most studies had been done during initial implementation of the robotic technique. Therefore, we believe that robotic technique could be superior to the conventional laparoscopic technique for lymphadenectomy. Since the history of the clinical application of RG is a short one, few reports have compared long-term survival outcomes with other methods. Coratti et al. [53] demonstrated that the 5-year survival rate after RG stratified with Stage IA, IB, II, and III was $100 \%$, 84.6\%, $76.9 \%$, and $21.5 \%$, respectively. Pugliese et al. [11] reported a cumulative overall 5-year survival rate of $78 \%$ with a mean follow up of 30 months (range 2-86) after RG for gastric cancer.

The application of robotic surgery remains controversial, mainly due to the considerable expense. The total difference in cost between the LG and RG groups has been predicted to be around 3900 USD [18, 31, 38], which is mainly derived from the robotic system itself. According to the opinions of some investigators, the higher cost of robotic surgery is not enough to justify the theoretical advantages of this technology [54]. If RG can reduce complications and shorten hospital stay, the higher costs of the robotic system would be partially offset. Based on this, it is essential for robotic operators to inspect whether the potential advantages of the robotic approach justifies its high cost in the treatment of gastric cancer.

Our research has the following limitations: (1) Selection bias: As no RCT was available to be included in the meta-analysis due to the higher cost of robotic surgery, selection biases are inevitable in surgical abstention which should be carefully interpreted. (2) Clinical heterogeneity: The homogeneity test for the continuous variables exhibited substantial heterogeneity due to the inherent flaws of a retrospective study, the uneven surgical skills of the different surgeons, as well as regional differences, etc. More importantly, for surgeons in the East, radical distal gastrectomy for middle and distal gastric cancer is popular [55], while the distal subtotal is preferred in the West [56]. Thus we cataloged distal gastrectomy and subtotal gastrectomy as a subgroup. Though it brings some interesting results due to the expansion of sample size, such a combination would result in clinical heterogeneity. (3) Regional difference: The majority of the included studies came from East Asia, because East Asia has the highest prevalence of gastric cancer, while gastric cancer is relatively uncommon in Western countries. Besides, in East Asia, particularly Korea, Japan and some areas of China, the proportion of early gastric cancer has increased as a result of the improved surveillance of gastric cancer in these regions $[57,58]$. On the other hand, although increasing evidence continues to show no difference between patients undergoing open or laparoscopic surgery for oncologic outcomes, the Japanese Gastric Cancer Association still classifies minimal invasive surgery as investigational treatment and only recommends minimal invasive surgery for early stage gastric cancer patients [55]. Therefore, the cases in our studies, especially those from East Asia, were mainly early stage cases. All of the above limitations must be kept in mind when interpreting the results of our study.

\section{Conclusions}

Except for the longer operation time and higher costs, RG for the patients with gastric cancer was not inferior to LG. Besides; RG holds the potential benefits for larger numbers of lymph node dissection and reduced intraoperative blood loss. Further prospective studies are needed in order to confirm these advantages. In addition, long-term results are needed, particularly for the oncological adequacy of robotic gastric cancer resections.

\section{Abbreviations \\ BMI: body mass index; EBL: estimated blood loss; LG: laparocopic gastrectomy; LOS: length of hospital stay; NOS: Newcastle-Ottawa Quality Assessment Scale; RCT: randomized controlled trial; RG: robotic gastrectomy; RLN: retrieved lymph nodes; RR: risk ratio; SD: standard deviation; WMD: weighted mean difference}

Acknowledgments

Not applicable.

Funding

Not applicable.

Availability of data and materials

The datasets analyzed during the current study available from the corresponding author on reasonable request.

\section{Authors' contributions}

KC and YP designed the study; BZ and XFW collected literatures and conducted the analysis of pooled data; HM helped to draft the manuscript; KC and YP wrote the manuscript; XJC proofread and revised the manuscript. All authors have approved the version to be published.

Competing interest

The authors declare that they have no competing interests. 


\section{Ethics approval and consent to participate}

Not applicable.

\section{Consent for publication}

Not applicable.

\section{Publisher's Note}

Springer Nature remains neutral with regard to jurisdictional claims in published maps and institutional affiliations.

\section{Author details}

'Department of General Surgery, Sir Run Run Shaw Hospital, School of Medicine, Zhejiang University, 3 East Qingchun Road, Hangzhou, Zhejiang Province 310016, China. ${ }^{2}$ School of Medicine, Zhejiang University, 866 Yuhangtang Road, Hangzhou, Zhejiang Province 310058, China.

\section{Received: 11 June 2017 Accepted: 17 August 2017}

\section{Published online: 24 August 2017}

\section{References}

1. Chen K, Mou YP, Xu XW, Pan Y, Zhou YC, Cai JQ, et al. Comparison of shortterm surgical outcomes between totally laparoscopic and laparoscopicassisted distal gastrectomy for gastric cancer: a 10-y single-center experience with meta-analysis. J Surg Res. 2015;194:367-74.

2. Chen K, Wu D, Pan Y, Cai JQ, Yan JF, Chen DW, et al. Totally laparoscopic gastrectomy using intracorporeally stapler or hand-sewn anastomosis for gastric cancer: a single-center experience of 478 consecutive cases and outcomes. World J Surg Oncol. 2016;14:115.

3. Chen K, He Y, Cai JQ, Pan Y, Wu D, Chen DW, et al. Comparing the shortterm outcomes of intracorporeal esophagojejunostomy with extracorporeal esophagojejunostomy after laparoscopic total gastrectomy for gastric cancer. BMC Surg. 2016;16:13

4. Chen K, Xu XW, Zhang RC, Pan Y, Wu D, Mou YP. Systematic review and meta-analysis of laparoscopy-assisted and open total gastrectomy for gastric cancer. World J Gastroenterol. 2013:19:5365-76.

5. Rockall TA, Darzi A. Robot-assisted laparoscopic colorectal surgery. Surg Clin North Am. 2003:83:1463-8. xi

6. Gutt CN, Oniu T, Mehrabi A, Kashfi A, Schemmer P, Buchler MW. Robotassisted abdominal surgery. Br J Surg. 2004:91:1390-7.

7. Song J, Oh SJ, Kang WH, Hyung WJ, Choi SH, Noh SH. Robot-assisted gastrectomy with lymph node dissection for gastric cancer: lessons learned from an initial 100 consecutive procedures. Ann Surg. 2009;249:927-32.

8. Grobmyer SR, Pieracci FM, Allen PJ, Brennan MF, Jaques DP. Defining morbidity after pancreaticoduodenectomy: use of a prospective complication grading system. J Am Coll Surg. 2007;204:356-64.

9. Hozo SP, Djulbegovic B, Hozo I. Estimating the mean and variance from the median, range, and the size of a sample. BMC Med Res Methodol. 2005;5:13.

10. Harr JN, Luka S, Kankaria A, Juo YY, Agarwal S, Obias V. Robotic-assisted colorectal surgery in obese patients: a case-matched series. Surg Endosc. 2017:31:2813-9.

11. Pugliese R, Maggioni D, Sansonna F, Ferrari GC, Forgione A, Costanzi A, et al. Outcomes and survival after laparoscopic gastrectomy for adenocarcinoma. Analysis on 65 patients operated on by conventional or robot-assisted minimal access procedures. Eur J Surg Oncol. 2009:35:281-8.

12. Uyama I, Kanaya S, Ishida Y, Inaba K, Suda K, Satoh S. Novel integrated robotic approach for suprapancreatic $D_{2}$ nodal dissection for treating gastric cancer: technique and initial experience. World J Surg. 2012;36:331-7.

13. Huang KH, Lan YT, Fang WL, Chen JH, Lo SS, Hsieh MC, et al. Initial experience of robotic gastrectomy and comparison with open and laparoscopic gastrectomy for gastric cancer. J Gastrointest Surg. 2012;16:1303-10.

14. Song J, Kang WH, Oh SJ, Hyung WJ, Choi SH, Noh SH. Role of robotic gastrectomy using da Vinci system compared with laparoscopic gastrectomy: initial experience of 20 consecutive cases. Surg Endosc. 2009; 23:1204-11.

15. Woo Y, Hyung WJ, Pak KH, Inaba K, Obama K, Choi SH, et al. Robotic gastrectomy as an oncologically sound alternative to laparoscopic resections for the treatment of early-stage gastric cancers. Arch Surg. 2011 146(9):1086-92.

16. Kim HI, Park MS, Song KJ, Woo Y, Hyung WJ. Rapid and safe learning of robotic gastrectomy for gastric cancer: multidimensional analysis in a comparison with laparoscopic gastrectomy. Eur J Surg Oncol. 2014;40:1346-54.
17. Okumura N, Son T, Kim YM, Kim HI, An JY, Noh SH, et al. Robotic gastrectomy for elderly gastric cancer patients: comparisons with robotic gastrectomy in younger patients and laparoscopic gastrectomy in the elderly. Gastric Cancer. 2016:19:1125-34.

18. Eom BW, Yoon HM, Ryu KW, Lee JH, Cho SJ, Lee JY, et al. Comparison of surgical performance and short-term clinical outcomes between laparoscopic and robotic surgery in distal gastric cancer. Eur J Surg Oncol. 2012;38:57-63.

19. Yoon HM, Kim YW, Lee JH, Ryu KW, Eom BW, Park JY, et al. Robot-assisted total gastrectomy is comparable with laparoscopically assisted total gastrectomy for early gastric cancer. Surg Endosc. 2012;26:1377-81.

20. Park JY, Jo MJ, Nam BH, Kim Y, Eom BW, Yoon HM, et al. Surgical stress after robot-assisted distal gastrectomy and its economic implications. Br J Surg. 2012;99:1554-61.

21. Kim YW, Reim D, Park JY, Eom BW, Kook MC, Ryu KW, et al. Role of robotassisted distal gastrectomy compared to laparoscopy-assisted distal gastrectomy in suprapancreatic nodal dissection for gastric cancer. Surg Endosc. 2016;30:1547-52.

22. Pugliese R, Maggioni D, Sansonna F, Costanzi A, Ferrari GC, Di Lernia S, et al. Subtotal gastrectomy with $D_{2}$ dissection by minimally invasive surgery for distal adenocarcinoma of the stomach: results and 5-year survival. Surg Endosc. 2010;24:2594-602.

23. Kim MC, Heo GU, Jung GJ. Robotic gastrectomy for gastric cancer: surgical techniques and clinical merits. Surg Endosc. 2010;24:610-5.

24. Kim KM, An JY, Kim HI, Cheong JH, Hyung WJ, Noh SH. Major early complications following open, laparoscopic and robotic gastrectomy. $\mathrm{Br}$ J Surg. 2012;99:1681-7.

25. Son SY, Lee CM, Ahn SH, Lee JH, Park DJ, Kim HH. Clinical outcome of robotic Gastrectomy in gastric cancer in comparison with laparoscopic Gastrectomy: a case-control study. Journal of Minimally Invasive Surgery. 2012;15:27-31

26. Kang BH, Xuan Y, Hur H, Ahn CW, Cho YK, Han SU. Comparison of surgical outcomes between robotic and laparoscopic Gastrectomy for gastric cancer: the learning curve of robotic surgery. J Gastric Cancer. 2012;12:156-63.

27. Zhang $X L$, Jiang ZW, Zhao K. Comparative study on clinical efficacy of robot-assisted and laparoscopic gastrectomy for gastric cancer. Zhonghua Wei Chang Wai Ke Za Zhi. 2012;15:804-6.

28. Hyun $\mathrm{MH}$, Lee $\mathrm{CH}$, Kwon YJ, Cho SI, Jang YJ, Kim DH, et al. Robot versus laparoscopic gastrectomy for cancer by an experienced surgeon: comparisons of surgery, complications, and surgical stress. Ann Surg Oncol. 2013;20:1258-65.

29. Son T, Lee JH, Kim YM, Kim HI, Noh SH, Hyung WJ. Robotic spleenpreserving total gastrectomy for gastric cancer: comparison with conventional laparoscopic procedure. Surg Endosc. 2014;28:2606-15.

30. Noshiro H, Ikeda O, Urata M. Robotically-enhanced surgical anatomy enables surgeons to perform distal gastrectomy for gastric cancer using electric cautery devices alone. Surg Endosc. 2014;28:1180-7.

31. Huang KH, Lan YT, Fang WL, Chen JH, Lo SS, Li AF, et al. Comparison of the operative outcomes and learning curves between laparoscopic and robotic gastrectomy for gastric cancer. PLoS One. 2014;9:e111499.

32. Junfeng Z, Yan S, Bo T, Yingxue H, Dongzhu Z, Yongliang Z, et al. Robotic gastrectomy versus laparoscopic gastrectomy for gastric cancer: comparison of surgical performance and short-term outcomes. Surg Endosc. 2014;28: 1779-87.

33. Liu J, Ruan H, Zhao K, Wang G, Li M, Jiang Z. Comparative study on da Vince robotic and laparoscopic radical gastrectomy for gastric cancer. Zhonghua Wei Chang Wai Ke Za Zhi. 2014;17:461-4.

34. Lee J, Kim YM, Woo Y, Obama K, Noh SH, Hyung WJ. Robotic distal subtotal gastrectomy with $\mathrm{D}_{2}$ lymphadenectomy for gastric cancer patients with high body mass index: comparison with conventional laparoscopic distal subtotal gastrectomy with $D_{2}$ lymphadenectomy. Surg Endosc. 2015;29: 3251-60.

35. Han DS, Suh YS, Ahn HS, Kong SH, Lee HJ, Kim WH, et al. Comparison of surgical outcomes of robot-assisted and laparoscopy-assisted pyloruspreserving Gastrectomy for gastric cancer: a propensity score matching analysis. Ann Surg Oncol. 2015;22:2323-8.

36. Park JY, Ryu KW, Reim D, Eom BW, Yoon HM, Rho JY, et al. Robot-assisted gastrectomy for early gastric cancer: is it beneficial in viscerally obese patients compared to laparoscopic gastrectomy? World J Surg. 2015;39:1789-97.

37. Suda K, Man IM, Ishida Y, Kawamura Y, Satoh S, Uyama I. Potential advantages of robotic radical gastrectomy for gastric adenocarcinoma in 
comparison with conventional laparoscopic approach: a single institutional retrospective comparative cohort study. Surg Endosc. 2015;29:673-85.

38. Kim HI, Han SU, Yang HK, Kim YW, Lee HJ, Ryu KW, et al. Multicenter prospective comparative study of robotic versus laparoscopic Gastrectomy for gastric Adenocarcinoma. Ann Surg. 2016;263:103-9.

39. Shen W, Xi H, Wei B, Cui J, Bian S, Zhang K, et al. Robotic versus laparoscopic gastrectomy for gastric cancer: comparison of short-term surgical outcomes. Surg Endosc. 2016;30:574-80.

40. Cianchi F, Indennitate G, Trallori G, Ortolani M, Paoli B, Macri G, et al. Robotic vs laparoscopic distal gastrectomy with $D_{2}$ lymphadenectomy for gastric cancer: a retrospective comparative mono-institutional study. BMC Surg. 2016;16:65

41. Hwang SH, Park DJ, Jee YS, Kim HH, Lee HJ, Yang HK, et al. Risk factors for operative complications in elderly patients during laparoscopy-assisted gastrectomy. J Am Coll Surg. 2009:208:186-92.

42. Patel MN, Aboumohamed A, Hemal A. Does transition from the da Vinci S to xi robotic platform impact single-docking technique for robot-assisted laparoscopic nephroureterectomy? BJU Int. 2015;116:990-4.

43. Morelli L, Guadagni S, Di Franco G, Palmeri M, Caprili G, D'Isidoro C, et al. Use of the new da Vinci xi during robotic rectal resection for cancer: a pilot matched-case comparison with the da Vinci Si. Int J Med Robot. 2017:13:e1728.

44. Jin SH, Kim DY, Kim H, Jeong IH, Kim MW, Cho YK, et al. Multidimensional learning curve in laparoscopy-assisted gastrectomy for early gastric cancer. Surg Endosc. 2007;21:28-33.

45. Vinuela EF, Gonen M, Brennan MF, Coit DG, Strong VE. Laparoscopic versus open distal gastrectomy for gastric cancer: a meta-analysis of randomized controlled trials and high-quality nonrandomized studies. Ann Surg. 2012. 255:446-56.

46. Tokunaga M, Sugisawa N, Kondo J, Tanizawa Y, Bando E, Kawamura T, et al. Early phase II study of robot-assisted distal gastrectomy with nodal dissection for clinical stage IA gastric cancer. Gastric Cancer. 2014;17:542-7.

47. Tokunaga M, Makuuchi R, Miki Y, Tanizawa Y, Bando E, Kawamura T, et al. Late phase II study of robot-assisted gastrectomy with nodal dissection for clinical stage I gastric cancer. Surg Endosc. 2016;30:3362-7.

48. Kim HH, Han SU, Kim MC, Hyung WJ, Kim W, Lee HJ, et al. Long-term results of laparoscopic gastrectomy for gastric cancer: a large-scale case-control and case-matched Korean multicenter study. J Clin Oncol. 2014;32:627-33.

49. Chen K, Xu X, Mou Y, Pan Y, Zhang R, Zhou Y, et al. Totally laparoscopic distal gastrectomy with $D_{2}$ lymphadenectomy and Billroth II gastrojejunostomy for gastric cancer: short- and medium-term results of 139 consecutive cases from a single institution. Int J Med Sci. 2013;10:1462-70.

50. Sugimoto M, Kinoshita T, Shibasaki H, Kato Y, Gotohda N, Takahashi S, et al. Short-term outcome of total laparoscopic distal gastrectomy for overweight and obese patients with gastric cancer. Surg Endosc. 2013;27:4291-6.

51. Chen K, Pan Y, Zhai ST, Cai JQ, Chen QL, Chen DW, et al. Laparoscopic gastrectomy in obese gastric cancer patients: a comparative study with non-obese patients and evaluation of difference in laparoscopic methods. BMC Gastroenterol. 2017;17:78.

52. Wang Z, Zhang X, Liang J, Hu J, Zeng W, Zhou Z. Short-term outcomes for laparoscopy-assisted distal gastrectomy for body mass index $>/=30$ patients with gastric cancer. J Surg Res. 2015;195:83-8.

53. Coratti A, Fernandes E, Lombardi A, Di Marino M, Annecchiarico M, Felicioni $L$, et al. Robot-assisted surgery for gastric carcinoma: five years follow-up and beyond: a single western center experience and long-term oncological outcomes. Eur J Surg Oncol. 2015;41:1106-13.

54. Park JS, Choi GS, Park SY, Kim HJ, Ryuk JP. Randomized clinical trial of robotassisted versus standard laparoscopic right colectomy. Br J Surg. 2012;99: 1219-26.

55. Japanese Gastric Cancer Association. Japanese gastric cancer treatment guidelines 2014 (ver. 4). Gastric Cancer. 2017:20:1-19.

56. De Manzoni G, Marrelli D, Baiocchi GL, Morgagni P, Saragoni L, Degiuli M, et al. The Italian research Group for Gastric Cancer (GIRCG) guidelines for gastric cancer staging and treatment: 2015. Gastric Cancer. 2017;20:20-30.

57. Inoue $\mathrm{M}$, Tsugane S. Epidemiology of gastric cancer in Japan. Postgrad Med J. 2005;81:419-24.

58. Jeong O, Park YK. Clinicopathological features and surgical treatment of gastric cancer in South Korea: the results of 2009 nationwide survey on surgically treated gastric cancer patients. J Gastric Cancer. 2011;11:69-77. 